\title{
O QUE A JUVENTUDE NEGRA DO SLAM TEM A DIZER PARA A PSICOLOGIA SOCIAL?
}

\author{
WHAT DO SLAM BLACK YOUTH HAVE \\ TO SAY TO SOCIAL PSTCHOLOGY? \\ ¿QUÉ TIENEN QUE DECIR LA JUVENTUD NEGRA \\ DEL SLAM A LA PSICOLOGÍA SOCIAL?
}

\author{
Maíne Alves Prates ${ }^{1}$, Neuza Maria de Fátima Guareschi ${ }^{1}$ \\ e Carolina dos Reis ${ }^{1}$
}

${ }^{1}$ Universidade Federal do Rio Grande do Sul, Porto Alegre/RS, Brasil

\begin{abstract}
RESUMO: Este trabalho discute como as poesias no slam tensionam a sociedade no contexto do racismo em suas diversas dimensões. As rodas de slam são um espaço onde slammers expõem manifestos poéticos sobre racismo e formas de opressão e onde a juventude negra se inscreve no mundo por meio de sua narrativa, interagindo com seus iguais e produzindo relações que fortalecem, legitimam e valorizam suas vivências. A partir da abordagem afrocêntrica e afrorreferenciada, tomamos poesias de slammers como materialidade para problematizar o lugar que a temática racial ocupa na Psicologia Social, pensando o social como um campo problemático construído e produzido a partir de diferentes práticas humanas. Com isso, podemos abrir na roda da psicologia social uma fenda que desloca a produção de conhecimento a partir da pluriversalidade, ou seja, as possibilidades de as rodas de slam convidarem a psicologia social a compor teorias localizadas fora do círculo acadêmico ocidentocêntrico.
\end{abstract}

PALAVRAS-CHAVE: Slam; Juventude Negra; Psicologia Social; Afrocentricidade; Pluriversalidade.

RESUMEN: Este trabajo analiza cómo la poesía en slam tensiona a la sociedad en el contexto del racismo en sus diversas dimensiones. Las ruedas de slam son espacios donde los slammers exponen manifiestos poéticos sobre el racismo y las formas de opresión y donde los jóvenes negros se inscriben en el mundo a través de su narrativa, interactuando con sus pares y produciendo relaciones que fortalecen, legitiman y valoran sus vivencias. Desde un enfoque afrocéntrico y afroreferenciado, tomamos la poesía de slammers como materialidad para problematizar el lugar que ocupan los temas raciales en la Psicología Social, pensando en lo social como un campo problemático construido y producido a partir de diferentes prácticas humanas. Con esto, podemos abrir una brecha en la rueda de la psicología social que desplaza la producción de conocimiento de la pluriversalidad, es decir, las posibilidades de ruedas de slam para invitar a la psicología social a componer teorías ubicadas fuera del círculo académico occidental-céntrico.

PALABRAS CLAVE: Slam; Juventud Negra; Psicología Social; Afrocentricidad; Multiversalidad.

ABSTRACT: This paper discusses how poetry in slam tensions society in the context of racism in its various dimensions. The slam wheels are spaces where slammers expose poetic manifestos about racism and other forms of oppression, and where black youth are inscribed in the world through their narratives, interacting with their peers and producing relations that strengthen, legitimize and value their experiences. From an Afrocentric and Africanreferenced approach, we take slammers poetry as materiality to problematize the place that racial themes occupy in Social Psychology, thinking of the social as a problematic field constructed and produced from different human practices. With this, we can open a crack in the circle of social psychology that displaces the production of knowledge from pluriversality, that is, the possibilities of slam wheels to invite social psychology to compose theories outside the Western-centered academic circle.

KEYWORDS: Slam; Black Youth; Social Psychology; Afrocentricity; Multiversity. 


\section{Introdução}

Slam Poetry ou Slam são batalhas de poesias individuais, em duplas ou em grupos, com temáticas diversas do cotidiano, tais como: racismo, sexismo, discriminação de LGBTQI+, política, educação, relacionamentos amorosos, sexualidades. Os slams em Porto Alegre-RS geralmente ocorrem em praças e em alguns bares e tem como principais atores a juventude negra e periférica. O primeiro slam no Rio Grande do Sul ocorreu em 2016 com o slam das minas inspirado no slam das minas de Brasília, coletivo exclusivo para a apresentação de mulheres, e o segundo foi o slam peleia. Havia também os coletivos do interior: o Slam da Montanha, de Caxias do Sul, o Slam Liberta, de Esteio, o Slam Poesia, de Pelotas e o Slam Novo Hamburgo (Carapeços, 2017).

A ganhadora de cada slam disputa a final regional com outros coletivos do Rio Grande do Sul. Após a final regional duas pessoas disputam o slam nacional em São Paulo onde a pessoa representa o Brasil na final internacional na França. Para participar, a pessoa deve ter poesias de autoria própria e recitar em até três minutos para o público que se distribui em formato de roda onde a pessoa poeta, chamada de slammer, fica no meio da roda recebendo energia e incentivo. Pessoas juradas são selecionadas pela organização do slam e são responsáveis por dar uma nota de 0 a 10 para cada poesia, atentas a poesia e a performance de quem recita. A soma de pontos é o que determina a classificação da slammer. Durante o intervalo à soma de pontos é possível que pessoas não competidoras recitem poesias autorais ou não. Esse momento é chamado de verso livre.

Devido a pandemia causada pelo novo coronavírus, as poetas publicam suas obras e dividem a sensação de viver em contexto pandêmico mediante postagens nas redes sociais e/ou lives. As Live Slams acontecem nas redes e plataformas digitais, possibilitando a participação de poetas de todo o Brasil. A modalidade virtual não se difere da presencial com relação ao júri, as regras e a participação do público que, inclusive, é muito valorizada durante a competição.

As rodas de slam chamam a atenção por ser ocupada e protagonizada em sua maioria pela juventude negra em Porto Alegre, Rio Grande do Sul, estado conhecido pela colonização alemã e italiana. O tema racismo e suas manifestações são frequentes porém, junto com as denúncias, a positivação de ser negro aliada às mais diversas manifestações de afeto entre competidores fazem a emoção do grande público a cada apresentação. Muitos slammers desmistificam a ideia de batalha com o objetivo de individualista torcendo um pelo outro dentro da mesma competição. Por essa razão o slam provoca deslocamentos na produção de conhecimento dentro e fora da academia com produções escritas e eventos em que integrantes das rodas de poesia são convidadas a compor.

Sob o ponto de vista da psicologia, Alves, Costa e Castelar (2020) discutem que, embora a pauta do enfrentamento ao racismo tenha sido acolhida pelo Sistema Conselhos de Psicologia, "ainda havia, naquele contexto, uma dificuldade importante quanto à compreensão do racismo como estruturante da sociedade brasileira e, consequentemente, da produção de subjetividade de pessoas negras e brancas” (p. 1). Racismo entende-se como uma estratégia de dominação na qual historicamente teorias e práticas foram forjadas de modo a fundamentar uma hierarquização racial onde determinada raça ocupa uma posição privilegiada em detrimento de outras raças. 
A função básica do racismo é blindar os privilégios do segmento hegemônico da sociedade, cuja dominância se expressa por meio de um continuum de características fenotípicas, ao tempo que fragiliza, fraciona e torna impotente o segmento subalternizado. A estigmatização da diferença com o fim de "tirar proveito" (privilégios, vantagens, direitos) da situação assim criada é o próprio fundamento do racismo. Esse nunca poderia separar-se do conjunto dos processos sistêmicos que ele regula e sobre os quais preside tanto em nível nacional quanto internacional. (Moore, p. 284)

Evidencia-se até hoje a dificuldade de um posicionamento ético-político da psicologia social diante de discursos e práticas racistas, mesmo depois de duas décadas de produção de conhecimento sobre raça e racismo no campo psi (Alves, Costa, \& Castelar, 2020). Diante disso, faz-se necessário problematizar a psicologia social como "um efeito das tensões de saber e poder" (Flôres et al., 2021, p. 204).

Silva (2004) considera que a chave para compreender a invenção de uma psicologia social está na ideia de compreender o social não como uma mera evidência fundada no senso comum, como em fato natural intrínseco, mas como um campo problemático que emerge de um determinado conjunto de práticas, ou seja,

se o social existe entre os indivíduos, não é apenas em função das múltiplas interações que se produzem entre os mesmos, mas que é, sobretudo, numa espécie de interstício, marcado por uma multiplicidade de acontecimentos e de práticas que atravessam uma formação histórica num dado momento, que o social irá ganhar uma consistência e se constituir como um campo problemático. (Silva, 2004, p. 14)

Pensando que Conceição Evaristo concebeu o termo escrevivência pensando a narrativa de mulheres negras, o slam foi uma forma de pensar de que é possível a juventude negra escreviver. A autora afirma que as escritas não se dão só pelo alfabeto, mas são feitas pelo corpo, pelo gesto, pela voz e pela expressão. A juventude negra através do slam utiliza dessas possibilidades para recitar poesia. Embora entendamos que ela parte de um outro lugar em suas narrativas, mas que muitas experiências se atravessam. A escrevivência para Soares e Machado (2017) carrega uma dimensão ética ao propiciar que a autora "assuma o lugar de enunciação de um eu coletivo, de alguém que evoca, por meio de suas próprias narrativas e voz, a história de um 'nós' compartilhado" (p. 207), portanto as poesias destacadas neste trabalho conta a história de muitas pessoas negras poetas.

Nesse campo, em diálogo com a pluriversalidade de experiências que as rodas de poesias trazem para o campo do conhecimento, é que se faz emergente a questão: o que a juventude negra do slam tem a dizer para a psicologia social? Para responder esta pergunta partiremos do paradigma afrocêntrico em diálogo com os estudos afro referenciados e teorias racializadas para uma leitura do que essa experiência versada nas poesias da juventude negra aponta para psicologia social. 


\section{O slam versando com teorias afrocentradas e racializadas}

Entendemos como teorias racializadas aquelas em que a raça é colocada como categoria analítica. Como Zamora (2012) aponta, "se levada em conta como uma categoria analítica, raça e racismo é capaz de desvelar muitas formas de exercício de poder opressivo e de favorecer nosso entendimento da sociedade e da subjetividade que produz" (p. 564), ou seja, pesquisas que trazem à tona questões raciais tensionam diversos saberes que não são contemplados pelo saber hegemônico fundado no ocidentocentrismo.

Afrocentricidade é uma proposta epistemológica que vai trazer a África para o centro das discussões pensando o povo africano e sua diáspora como sujeitos e agentes de seus pensamentos e produções. De acordo com Mazama (2009) a afrocentricidade surge da ideia de autoconsciência e autodefinição positiva e assertiva, ou seja, a autoconsciência de nós africanos como agentes "não mais satisfeitos em ser definidos e manipulados de fora (p. 111).

A ideia de diáspora, conforme Abdias Nascimento (2019), vai além da ideia de dispersão, em que descendentes de africanos foram espalhados aos quatro cantos do universo."Constituímos a diáspora do regresso; somos os povos negros que se voltam, em ritmo concêntrico, rumo à origem prístina do espírito e da história dos ancestrais, a fim de projetar o futuro" (p. 186), ou seja, ser africana em diáspora é um exercício consciente de busca pelo legado dos antepassados africanos e, consequentemente, por toda a história africana, apagada sob a égide da supremacia branca, pensando-se na construção da história africana para as próximas gerações pela narrativa de seu povo.

Os estudos afrocentrados, afrorreferenciados e racializados, a partir da perspectiva da pessoa negra/africana, discutem a localização das referências que produzem a concepção de "gueto", do "Outro", do "periférico"; por conseguinte, possibilitam discutir a juventude negra tendo em conta a potência e a valorização da experiência de jovens negros/as. Entende-se o processo de afrocentramento como uma abertura de possibilidades para múltiplas formas de ser africano e como uma fenda que se abre para o deslocamento da produção de conhecimento a partir da pluriversalidade, que, segundo Ramose (2011), em oposição à universalidade, reflete as diversas localizações onde a filosofia se encontra para pensar a experiência de ser humano.

No contex to brasileiro, Gaia e Scorsolini-Comin (2020) defendem que o Brasil é composto por uma herança africana, não necessariamente afrocentrada, mas afrorreferenciada. Conforme os autores, o encontro de múltiplas culturas propiciou, no solo brasileiro, o que chamam de "hibridismo que permite a existência de múltiplas perspectivas de ser negro, de ser africano e/ou sobre a própria África no Brasil” (p. 3).

Há, dentro das artes, muitas referências que expressam um sentimento de busca por uma subjetividade sequestrada e o reconhecimento e resgate de uma história apagada. Esse movimento, no entanto, não é necessariamente entendido como afrocentrista, pois não se trata de colocar a África como centro, mas de uma busca da positivação da negritude. De acordo com os autores, a afrocentricidade no Brasil acontece em grande parte fora da academia, por ser esta, evidentemente, um espaço com moldes não africanos; eles dão como exemplos de práticas afrocentradas como os terreiros de Candomblé e a prática do Yoga Kemetico. 
As poesias das rodas de slam recitadas, performadas pela juventude negra poeta, colocam em jogo resistências, denúncias, afetos e potência. Tem-se o ato de trazer à tona a tradição oral: conhecimento africano ancestral de contar histórias e de colocar-se no mundo pelo poder das palavras. Indaga-se uma forma de produzir conhecimento localizada na cosmopercepção africana, e não na cosmovisão do Ocidente.

No estudo de Oyěwùmí (2002), o termo cosmovisão é usado para resumir a lógica cultural do Ocidente, concebida pela visão, isto é, uma concepção de mundo que passa apenas por aquilo que os olhos podem ver, ler e registrar. Diferentemente de outras culturas, como os povos iorubás, que privilegiam a tradução do mundo de outros sentidos diferentes da visão, ou até mesmo de combinações de sentidos, como o ouvir e o sentir.

O6 de abril de 2020

(Julinho)

Era uma vez

Um garoto

Que morava em uma torre

No alto de um morro

(...)

Via da janela o mundo

Mas não podia telo

Via o chão mas não podia causálo

Via da janela o céu

Mas não conseguia tocá-lo

De sua torre não podia sair

Pois o medo não deixava ${ }^{1}$

06 de abril de 2020 é de um jovem, negro e poeta. Julinho escreve sobre a história de um garoto que morava no alto de uma torre onde da janela conseguia ver um mundo que não poderia ter e um céu que não poderia tocar. Morava em um lugar onde não poderia sair, pois medo não deixava. Essa jornada de Julinho faz pensar sobre um processo de descoberta de um mundo onde gostaria que pudesse aceitá-lo - aceitar um jovem negro poeta tal qual ele é, com a sua cultura e a sua forma de expressar-se. Porém, esse mundo não existe para ele. Será que não existe ou esse mundo foi forjado para não existir?

Sueli Carneiro (2005) abordará o termo epistemicídio considerado pela autora como um dos elementos constitutivos do dispositivo da racialidade compondo a teoria de biopoder de Foucault. Carneiro afirma que o eu "no encontro com a racialidade ou etnicidade, adquiriu superioridade pela produção do inferior, pelo agenciamento que essa superioridade produz sobre a razoabilidade, a normalidade e a vitalidade" (p. 42), ou seja, posto que para Foucault o sujeito é efeito das práticas discursivas o dispositivo de racialidade será a dualidade de um positivo e um negativo sendo a brancura o fator de identificação do normal. O dispositivo tem uma função estratégica dominante e de poder, pois surge para responder a uma urgência formada por um determinado momento histórico. O primeiro passo para a constituição de um dispositivo é demarcar seus componentes heterogêneos; o segundo é demarcar a natureza da relação desses elementos. 
Pensando em melhor entender e visualizar o que seria um dispositivo, faz-se uma analogia meramente didática com uma roda de slam. Essa roda, com poemas carregados de discursos, leis, lógicas, dentre outras expressões ditas e não ditas, oferece um campo onde relações de poder, práticas e saberes se articulam. O dispositivo instaura uma prática divisora em que "a enunciação sobre o Outro constitui uma 'função de existência" (Carneiro, 2005, p. 39), quer dizer, no slam, revelam-se relações de poder, práticas e saberes que enunciam a demarcação de ser "branco", "negro", "cidadão", "marginal”, "humano”, "aberração”, "animal”, "normal”, "patológico” - enfim, a demarcação de tudo que constitui o "sujeitoforma” onde se produz o ser humano e o Outro.

Esse eu (branco) que produz o Outro para a afirmação de si “irá por consequência redefinir todas as demais dimensões humanas e hierarquizá-las de acordo com a sua proximidade ou distanciamento desse padrão" (Carneiro, 2005, p. 43). O epistemicídio, elemento do dispositivo de racialidade,

se constituiu e se constitui como num dos instrumentos mais eficazes e duradouros de dominação étnica/racial pela negação que empreende da legitimidade das formas de conhecimento, do conhecimento produzido pelos grupos dominados e, consequentemente, de seus membros enquanto sujeitos de conhecimento. (Carneiro, 2005, p. 96)

Para legitimar o conhecimento de um determinado grupo dominante, é preciso negar, deslegitimar o conhecimento de grupos dominados e essa foi a estratégia para a expansão europeia e para a formulação plena do racialismo do século XIX. Carneiro (2005) encontra, na concepção de Boaventura Souza Santos, os nexos na forma pela qual a tradição filosófica ocidental integra e exclui a diversidade para fins de, em resumo, subordinação dos Outros, condicionando-os como "colonizados/tutelados, dependentes" (p. 97).

Agora, façamos o exercício de pensar o dispositivo de racialidade e o poema de Julinho nessa afirmação. Para que um sujeito seja superior, humano, normal, ou seja, enquadrado nas definições de um "Ser pleno", Sueli afirma que há uma estratégia de constituição do sujeito negro como inferior. Para se constituir essa inferioridade, há uma deslegitimação desse sujeito como portador e produtor de conhecimento. Assim, o conhecimento de poesia e de arte que se diz brasileiro e generalista, carregado de normas, padrões e lógicas, é o mesmo que deslegitima uma produção de conhecimento quando este não se enquadra nas normas.

Podemos pensar que essa torre que Julinho poemiza em sua história foi construída em uma estrutura regada de falsas informações. Essa imensa torre é estrategicamente construída para impedir o jovem negro poeta de acessar o mundo, a não ser que ele ganhe as pessoas, igualando-se a um discurso que o deixa vazio. 
Ao invés de xingar o mundo por invejá-lo

Preferiu criticá-lo pra ganhar as pessoas pois elas acabaram sendo uma grande parte dele

E depois de ter conseguido o mundo de um jeito ou de outro

Acabou-se insatisfeito

Sua única ambição se torno só alguma coisa

(...)

Tudo se torno nada

O nada se torno vago

E assim acabou criando seu vazio

No qual acabou morando

E conhecendo um amigo

Que sempre lê falava

Até no vazio a alguém

Sinta, até no vazio a alguma coisa.

Um vazio é preenchido por sua imaginação, incompreendida por um mundo em que ele não se reconhece. Esse mundo onde ele é obrigado a igualar-se, e, para isso, ele precisa minimizar-se, "abrasileirar-se", ou melhor, embranquecer-se.

Entre numerosas formas de resistência que o negro manteve e incorporou para a manutenção de sua identidade pessoal e histórica, Beatriz Nascimento (2006) ressalta o quilombo (kilombo) como um marco na capacidade de resistência e organização do povo negro e como um espaço que assume um significado amplo de resistência negra em diversos espaços (não somente físicos). A autora aborda o conceito de quilombo por meio de um apanhado histórico, considerando-o como instituição no período pré-diáspora, passando para território de resistência ao chegar ao Brasil no período colonial, onde os negros se organizavam e combatiam o colonialismo, até considerá-lo como prática política.

Nesse espaço de prática política, diversas organizações negras - dos clubes negros fundados no período pós-abolição até os bailes black, o movimento hip hop e, atualmente, os slams - podem ser pensadas como território de ação, reflexão e resistência. Desenvolvese, dessa maneira, o que Beatriz Nascimento afirmaria ser o símbolo de todas as formas de resistência do povo negro em busca de maior valorização de sua herança: "o quilombo volta-se como código que reage ao colonialismo cultural, reafirma a herança africana e busca um modelo brasileiro capaz de reforçar a identidade étnica" (Nascimento, 2006, p. 124).

Abdias Nascimento (2019) ao insistir na defesa dos valores africanos de cultura, religião, arte, organização social, história e visão de mundo, afirma que "Há um entrelaçamento inseparável de aspectos que, somados, constituem a totalidade histórico-existencial e metafísica, que entendo como sendo a cultura” (Nascimento, 2019, p. 177).

Começa-se a pensar a torre de Julinho sob outras perspectivas. O poeta retrata em sua arte um cenário de muitos jovens negros presos em torres criadas estrategicamente para que suas existências sejam diluídas em realidades opacas e vazias. Há um mundo onde jovens como ele não conseguem ver o chão e, não o vendo, não podem causá-lo, pois suas raízes foram arrancadas. O que seria causar o chão? A poesia pode ter várias interpretações. O chão pode ser pensado como o cotidiano. Segundo a poesia, ele está no alto de 
uma torre onde pode ver o chão, mas não pode tocar nele, não pode provocar nenhum tipo de mudança. Uma interpretação sobre isso é que um jovem negro vive em uma sociedade racista que utiliza do dispositivo de racialidade para inferiorizar a produção de conhecimento de jovens negros.

Logo, olhar para o chão e não conseguir causá-lo é, por exemplo, produzir uma poesia e não ser reconhecido como poeta ou ser minimizado, pois a arte de um jovem negro é incompreendida. Eis o epistemicídio pautado por Carneiro (2005). Outra forma de pensar o chão seria como enquadramento a padrões e normas nos obrigando a adequação não permitindo assim o rompimento para outras possibilidades de produção de conhecimento. Não podem tocar o céu, pois a máquina opressora não lhes dá tempo para vê-lo, quem dirá alcançá-lo. Mas até no vazio da poesia de Julinho há um amigo que o alerta para que "sinta, até no vazio há alguma coisa”.

A arte, para pessoas negras, opera como um diário e/ou como forma de denúncia e/ ou positivação das próprias experiências, ressaltando o entrelaçamento inseparável que Abdias Nascimento afirma, entre cultura afro-brasileira e outras reivindicações da gente negra, como a organização social. Considerando essas realidades opacas e vazias, resultado da diluição da multiplicidade de experiências de muitos jovens negros, Silva (2004) ajuda-nos a pensar sobre como o social também pode ser visto como algo opaco e vazio. A autora propõe o exercício de imaginar um psicólogo social perguntando para seus iguais o que seria o social. O objetivo não seria tirar uma definição, mas constatar, com um tom de espanto, as várias respostas levantadas, tamanha a ingenuidade da pergunta. Entretanto, essa questão traz à tona a de que trabalhar no social

nos impede muitas vezes de saber sobre o que exatamente nós trabalhamos, ... por essa razão, especificar a que estamos nos referindo quando empregamos o termo 'social' para caracterizar o terreno no qual se organiza nossa prática, pode nos ajudar a sair de vários impasses que resultam de uma compreensão ingênua a esse respeito. (Silva, 2004, p. 12)

Então, se a psicologia social propõe-se a pensar o social como um campo problemático, abrindo uma fenda para a multiplicidade de acontecimentos e práticas, atravessados por um momento histórico, a juventude negra nas rodas de slam propõe-se a compor essa fenda, trazendo em suas narrativas as consequências desse dispositivo de racialidade em suas experiências.

\section{Os efeitos do dispositivo de racialidade na literatura brasileira}

E ae, cê sabe o nome do seu avô? Eu sei o nome do meu. O nome dele é Roberto. Mas vamo mais além. Cê sabe de quem cê é bisneto? Eu não conheço o meu bisavô. Então fico quieto. Mas vamo pensar mais longe ainda estamos muito perto. Vamos pensar em ancestrais. Aliás, eu nem sei quem são os meus ancestrais. Eu sei que eles eram negros, mas o que eu sei mais? Nada. Sabe por quê? Minha raça foi vítima de aculturação. Para pra pensar quantos vocês veem se vangloriar por ser descendente de português, italiano e alemão. Eu não. Só sei que meus ancestrais eram pretos. E foram vítimas da escravidão. De resto. Eu não sei mais nada não... (A Cultura em ação, 2019) 
Os efeitos do dispositivo de racialidade podem ser identificados na construção da literatura no Brasil. Fonseca (2006) fornece-nos um panorama histórico, pontuando que, apesar de as expressões "literatura negra" e "literatura afro-brasileira" serem bastante utilizadas em meio acadêmico, seu sentido é questionado por serem consideradas como uma particularidade que não contemplaria a literatura brasileira de forma geral.

A expressão "literatura negra" surge no interior de movimentos dos Estados Unidos e do Caribe que se espalharam por outros espaços a fim de reconhecer e revalorizar a "herança cultural africana e da cultura popular, a escrita literária é assumida e utilizada para expressar um novo modo de se conceber o mundo" (Fonseca, 2006, pp. 11-12). Porém, para muitos teóricos e escritores do Brasil, das Antilhas, do Caribe e dos Estados Unidos, os termos "afro" e "negro", atrelados à literatura, são excludentes, uma vez que contemplam uma cultura em específico, uma particularidade artística e literária em especial; portanto, a cultura brasileira deveria ser levada em consideração, e não apenas a cultura negra.

Em contraponto, a autora afirma que outros teóricos entendem como necessária essa particularização, pois, quando se adota um termo abrangente, como no caso da literatura brasileira, para designar todas as formas literárias produzidas no Brasil, os "complexos conflitos de uma dada cultura ficam aparentemente nivelados e acabam sendo minimizados" (Fonseca, 2006, p. 12).

Abdias Nascimento (2019) argumenta que todo o processo de aculturação forçada vivida pelos africanos, resultado da imposição de valores ocidentais, acabou por deformar as obras literárias de muitos poetas e romancistas que mesmo utilizando pessoas negras como tema de suas obras, criaram para o consumo da classe dominante. Por essa imposição cultural histórica na cultura brasileira, entende-se o que Fonseca (2006) ressalta quanto ao poder de escolha sobre os textos que devem ser lidos e fazer parte dos programas escolares de literatura. Tal poder está nas mãos de um grupo de "privilegiados e/ou especialistas - os críticos. ... por isso, vale a pena aprofundar um pouco mais a discussão sobre a dificuldade de nomeação da arte e da literatura produzida por autores não 'eleitos' pela crítica" (Fonseca, 2006, p. 12).

Também, é possível refletir sobre o que Fonseca (2006) afirma sobre a resistência de escritores negros em posicionar-se como autores negros ou em nomear sua literatura como negra, por entenderem o termo como rotulador ou aprisionador de sua produção literária. Imprescindível ressaltar que aqui não se trata de uma crítica às obras clássicas, e sim de uma reflexão sobre as vicissitudes dentro das obras literárias produzidas por pessoas negras e sobre os efeitos do que Carneiro (2005) traz como dispositivo de racialidade, desvelando as muitas formas de exercício de poder opressivo e favorecendo nosso entendimento da sociedade e da subjetividade que ele produz (Zamora, 2012).

Percebe-se que muitos poetas no slam têm trazido sua ligação com a África em suas produções literárias, a exemplo de Hércules Marques (2019), conhecido como Jovem Preto Rei: "O que é nosso/é nosso/e defenderemos até a última consequência/um bom filho a casa torna/e nós/filhos de África/ nos tornamos resistência” (p. 21). Pensar a produção literária negra/africana deslocada da literatura hegemônica é evidenciar a existência de uma literatura que parte da localização do continente onde tudo começou para pessoas pretas em diáspora. 
Além disso, é pensar as diversas literaturas que enunciam pessoas negras/africanas como protagonistas, independentemente da nomenclatura atribuída a essa produção, a semelhança entre essas literaturas está na valorização da herança cultural negra/africana no Brasil e, principalmente, na produção de vida e de potência. "Tal processo se refere ao resgate, aproximação, reconhecimentos e partilhas não apenas de memórias, mas trata-se de um resgate cognitivo e ontológico de negros em diáspora” (Jesus, 2019, p. 257).

Por meio da poesia, conseguimos dar nome àquilo que não sabemos nomear nem dar forma em um primeiro momento, mas que já é sentido. Sentimento que Bâ (2010) descreveria como as potencialidades do saber, do poder e do querer que o criador de tudo (Maa Ngala) depositou em nós e que vão manifestar-se a partir do movimento da fala². $\mathrm{O}$ autor enfatiza a força que a tradição oral tem para os povos africanos: "nenhuma tentativa de penetrar a história e o espírito dos povos africanos terá validade a menos que se apóie nessa herança de conhecimentos de toda espécie, pacientemente transmitidos de boca a ouvido, de mestre a discípulo, ao longo dos séculos” (p. 167).

Sendo a fala manifestação das forças divinas herdadas pelo criador de tudo, os atos da fala e da escuta ganham um significado muito maior do que se costuma atribuir-lhes. A fala é força é a materialização das vibrações das forças de Maa Ngala, portanto, toda e qualquer manifestação do universo é considerada fala que ganha corpo e forma. Lorde (2020) ressalta:

quando entramos em contato com a nossa ancestralidade, com a consciência não europeia de vida como situação a ser experimentada e com a qual se interage, aprendemos cada vez mais a apreciar nossos sentimentos e a respeitar essas fontes ocultas do nosso poder - é delas que surge o verdadeiro conhecimento e, com ele, as atitudes duradouras. (p. 46)

Quando uma mulher negra entra na roda de poesia para recitar e recebe falas de força e incentivo de outras mulheres negras, isso diz do Kilombo de Beatriz Nascimento. A autora aponta, de acordo com Ratts (2006), para a importância desse movimento que os jovens fazem para conviver, identificar-se, conhecer um ao outro, dançar com o outro, pois isso faz com que se criem laços mais fortes entre os iguais e aumenta a autoestima. Beatriz, inclusive, ressalta o perigo de um intelectual negro que alcança certa ascensão distanciar-se de seu grupo. "Porque o grande drama da gente, a grande tragédia, é justamente a perda da compreensão do nosso passado, a perda do contato com o outro." (Nascimento, 1977b citado por Ratts, 2006, pp. 67-68).

Pessoas negras/africanas vivem o que Nobles (2009) chama de descarrilamento. $\mathrm{O}$ autor usa a metáfora do trem que continua em movimento mesmo fora dos trilhos, para descrever a vivência de pessoas negras mesmo fora da experiência e conscientização do que significa ser africano. "O caminho do desenvolvimento africano em termos de sociabilização, vida familiar, educação, formas de conhecer a Deus, padrões de governo, pensamento filosófico profundo, invenções científicas e técnicas foi descarrilhado pela invasão e dominação estrangeira” (p. 284) e isso impossibilita detectar os efeitos desse descarrilamento na vida de pessoas negras/africanas em diáspora, pois elas nunca viveram sua vida fora da experiência do ocidente. 
Percebe-se, na juventude negra, movimentos de afrorreferência que dizem respeito a um sentimento de busca por uma subjetividade sequestrada, pelo reconhecimento e resgate de uma história apagada (Gaia \& Scorsolini-Comin, 2020). Refletir, pesquisar, escreviver e recitar sobre ser descendente de africanos são movimentos que Nobles (2009) sugere como Sankofa a adinkras, que significa: "se você esquecer, não é proibido voltar atrás e reconstruir" (p. 277).

Para Nobles (2009), é importante declarar-se como africano, e engajar-se em atividades afrocentradas poderia ativar aspectos do espírito, contribuindo para a saúde mental: "não apenas compreender o significado e a experiência de ser africano, mas também de conhecer a utilidade e a realização da fé, da alegria e da beleza em ser, pertencer e tornar-se africano" (Nobles, 2009, p. 278). Mediante esses movimentos de pesquisa, conscientização e reflexão, a juventude negra, por meio do slam, traz em suas poesias a força do seu espírito, se aquilomba, se olha, se cuida, troca afetos, promove trabalhos independentes, fortalece seu quilombo e evidencia isso em redes sociais, eventos e intervenções artísticas.

A poesia de Belchior que introduz esse subtítulo provoca-nos para uma história que não foi contada de um determinado grupo social. O diário poético narrado pela juventude negra apresenta a continuidade de práticas racistas no Brasil que se perpetuam ainda nos dias de hoje (Vergne, Vilhena, Zamora, \& Rosa, 2015). Silva (2004) apresenta uma perspectiva genealógica para investigar a invenção da psicologia social por entender ser uma perspectiva que não busca uma origem ou uma identidade de algo, mas desnaturaliza aquilo que é dado como evidência, mostrando como o mesmo é historicamente construído.

A autora aponta que a primeira consequência na destruição do social como uma simples evidência é depararmo-nos com a multiplicidade. Isso significa admitir que existem várias configurações do social: "cada formação histórica cria um campo de possibilidades de onde emerge uma certa problemática que engendra, ao mesmo tempo, uma configuração específica do social" (Silva, 2004, p.14). A psicologia social se propõe a "compreender os dispositivos criados por uma determinada formação social no sentido de resolver os problemas aos quais ela se vê confrontada" (Silva, 2004, p. 14). Nesse sentido, há uma pista sinalizada pela juventude negra do slam sobre um campo a ser desenvolvido enquanto problemático sobre raça/racismo.

\section{O que a juventude negra do slam tem a dizer para a psicologia social?}

Porque gaúcho é visto com olho azul. Mas a verdade ninguém vê. E ninguém vê porque esconderam a Ilhota no fim da cidade. O bairro Colônia Africana hoje se chama Rio Branco. Tem preto no sul. Pro paulista isso causa espanto. Omitem nossa relevância na formação da sociedade. O Brasil fala em racismo velado, desculpa, ele é explícito no meu estado. Vejo paredes com o símbolo do nazismo pixado. ... Desmerecem o turbante. Tradição não é somente andar pilchado ${ }^{5}$. Isso não é uma carta de ódio. Polar pra mim $^{2}$ sempre vai ser o melhor trago. Mas nós engole seco cada coisa que já nem acho chimarrão assim tão amargo. (Tem Preto no Sul, 2018) 
A poesia de Bruno Negrão e Cristal conta a história negra no Rio Grande do Sul e ilustra, nas rimas, o apagamento de figuras negras em fatos históricos, além da deslegitimação da cultura negra no estado e, em específico, em Porto Alegre. Juventude que conhece sua história é uma juventude que carrega suas raízes e vai compartilhá-las com as próximas gerações. Pensando o saber formal e acadêmico centrado em uma estrutura ocidentocêntrica que nega outras formas de pensar a arte, vivências e existências, a juventude negra, no slam, tensiona conceitos produzidos sobre ela mesma por meio da poesia. Abdias Nascimento (2019) salienta sua confiança nos jovens negros do Brasil.

Vejo que eles estão acordados e alertas, plenos de confiança e esperança. Uma esperança séria, engajada e consequente, de quem não espera o futuro perdido nos sonhos, na contemplação ou na abstração da história. ... a juventude negra mostra possuir uma terrível consciência histórica da esperança, porque se acha imersa numa terrível situação que só permite e desesperança. (Nascimento, 2019, pp. 178-179)

A narrativa poética é ancestral. Desde o continente passando pela diáspora e o período da escravização até os dias de hoje, a poesia é uma forma de expressão que conta a história, dá vida ao corpo e ao espírito, e isso compõe a psique do povo africano. A força da oralidade é sentida antes, durante e depois do slam, que mobiliza palavras e inspira a poesia. Inspira a escrevivência, que não apenas "incomoda sonos injustos", mas também cria uma rede de afeto pelo compartilhamento de experiências semelhantes.

Alves, Costa e Castelar (2020) apontam a relevância de a psicologia "assumir um caminho ético-político de enfrentamento ao racismo em diferentes campos de práticas e de construção do conhecimento, na defesa da igualdade racial” (p. 1). As autoras destacam que o racismo é um assunto demasiadamente negado no Brasil, fazendo com que profissionais da psicologia não realizem uma análise histórica da relação entre o sofrimento vivenciado por pessoas negras e esse sistema de dominação que produz "efeitos sobre a vida material e a construção subjetiva de pessoas negras e brancas" (p. 3).

Segundo as autoras, a produção de psicologias antirracistas requer o entendimento do racismo enquanto episteme que estrutura nossa sociedade; sendo assim, seu enfrentamento deve ocorrer de modo "estruturante, e não transversal, de toda e qualquer ação ético-política da Psicologia enquanto ciência e profissão” (p. 4).

Flôres et al. (2021) questionam: o que pode a psicologia social em relação ao presente? O presente colocado diante dos autores é este cenário de ódio promovido pela extrema direita e pela reprodução de discursos fascistas que jamais deixaram de existir na sociedade, como se fosse um looping da história. Os autores apontam como problemática compreender em que medida temos sido capazes de produzir resistências às práticas de ódio, tão presentes em nossos cotidianos, assumindo que

a urgência da denúncia desta guerra sem fim se dá justamente pelo fato da guerra estar descendo das favelas, atingindo o asfalto. Os muros e as grades altas da classe média não protegem a porosidade do ódio. As universidades não são mais o lugar seguro e inabalável da crítica. (Flôres et al., 2021, p. 214) 
Essa guerra já é anunciada há muito tempo pela juventude negra e Agnes Mariá é uma das slammers que denunciam essa guerra anunciada:

Eles exigem que sejamos pacíficos, mas... Vai cobrar sensibilidade como se o governo tirou a filosofia do currículo? Eu sei é ridículo, obrigaram os nossos heróis a cruzar o Atlântico amontoados em navios como bichos. E agora tentam nos convencer de que quando se é preto, pobre e periférico, genocídio são ossos do ofício ... (Acorda, 2018)

Se Silva (2004) traz a existência do social como um interstício marcado por uma multiplicidade de acontecimentos e de práticas que atravessam uma formação histórica em um dado momento dando consistência para a formação de um campo problemático, retomamos a proposta da pluriversalidade de Ramose (2011). O autor concebe como pluriversalidade as mais diversas perspectivas particulares, específicas, reconhecidas e validadas como filosofias que explicam a pluriversalidade de experiências dos seres humanos.

Reivindicar que só há uma filosofia “universal” sem cultura, sexo, religião, história ou cor, é afirmar que a particularidade é um ponto de partida válido para a filosofia. Esta reivindicação não é explicitamente reconhecida com frequência pelos protagonistas da "universalidade" da filosofia. Esta é a razão pela qual eles estão dispostos a reconhecer nomes como Filosofia Ocidental, Chinesa, Indiana, Japonesa ou Russa, mas se recusam a reconhecer Filosofia Africana, Australasiana, Latino-americana, Maia e (até) mesmo filosofias feministas. Esta contradição simples é repugnante tanto para a lógica como para o senso comum. A contradição precisa ser solucionada através do reconhecimento da particularidade como um critério válido para toda ou para nenhuma filosofia. (Ramose, 2011, p. 11)

Inspirada pela roda de poesia composta por diversas experiências da juventude negra em convívio com a juventude não negra, formando assim uma grande roda pluriversal, a pluriversalidade vem dialogar com o intuito de localizar o slam, bem como a filosofia africana, que reivindica a particularidade como válida e viável para fazer e construir filosofia (Ramose, 2011).

Antes de pensar na pluralidade e na riqueza das diferenças, é necessária a análise honesta, não apenas da psicologia social, mas da academia de modo geral, principalmente das ciências humanas, em que por muito tempo a diferença foi negada e ainda hoje não é compreendida como possibilidade de produção de conhecimento. Não é concebível e nem sequer pensado que jovens poetas negros e periféricos possam ser fundamentação teórica de uma dissertação de mestrado, pois eles não têm expertise acadêmica para falar. É necessária uma pesquisa com autores acadêmicos que publiquem artigos científicos para falar sobre juventude negra? Por quê? A juventude negra poeta não tem expertise para falar sobre ela mesma?

Estamos falando muito mais do que colocar jovens como protagonistas de si. Estamos falando do que Mazama (2009, pp. 113-114) diz ser "reexaminar seu processo de sua conversão intelectual" para, em um segundo momento, reancorar, "de modo consciente e sistemático, em sua própria matriz cultural e histórica, dela extraindo os critérios para avaliar a experiência africana”. Estamos falando que Ama Mazama traz, em sua bagagem, 
a localização e implicação que ocupa para afirmar seu discurso, que tem tanta legitimidade, compromisso e responsabilidade quanto Tiatá, Agnes Mariá e outras poetas, porque diz de suas experiências.

A juventude negra, nas rodas de slam, desvela a multiplicidade de experiências que o social produz e evidencia que esse social nunca foi opaco - sempre foi preto. As rodas de poesia transformam dor, protesto, afeto e escrita científica em potências de vida, promovendo deslocamentos, abrindo fissuras em concepções que não colocam a juventude negra como agente de sua própria produção.

Se a psicologia se propõe a compreender o social como um campo problemático onde se abrem fendas para a multiplicidade de experiências atravessadas por múltiplas histórias, compondo um campo de conhecimento constantemente constituído, a juventude negra fundamenta a urgência de ser pensada a implicação da psicologia social na temática da raça/racismo. É preciso compreender que, para negros/africanos, existem percepções de ser e estar no mundo que vão além da racionalidade, da cosmovisão do ocidente, e que, para produzirmos psicologias antirracistas, devemos considerar diferentes epistemologias e as metodologias que as constituem (Alves, Costa, \& Castelar, 2020).

A psicologia social como máquina de guerra, conforme Flôres et al. (2021) propõem, faz-se urgente e necessária na atual conjuntura. Para complementar a construção dessa máquina, entendemos haver uma pluriversalidade de engrenagens para aniquilar a hegemonia epistêmica que ainda contribui para a reprodução de microfascismos na atualidade. Trata-se de "afirmar uma poética da existência que não faça da diferença inimigo, mas sim potência para a composição de modos de existir mais coloridos e alegres” (Flôres et al., 2021 , p. 218) As engrenagens devem estar demarcadas com suas devidas cores, conceitos, histórias, localizações geográficas e matrizes culturais. Não são borrões opacos que, misturando-se, produzem uma cor indefinida, sem brilho e sem vida. Juntas, compõem a infinidade das mais diversas experiências do que é ser humano.

\section{Notas}

1 Nesta poesia, assim como em todas as outras deste texto, optou-se em manter a caligrafia original como foram impressas as poesias pelos/as autores/as.

2 Bâ (2010) apresenta exemplos de tradições "da savana ao sul da Saara (que antigamente era chamada de Bafur e que constituía as regiões de savana da antiga África ocidental francesa)" (BÂ, 2010, p. 170). Falando a respeito de tradição oral, o autor afirma que não pode falar de qualquer tradição que não tenha vivido ou estudado pessoalmente. Isso exemplifica a responsabilidade e o comprometimento com a palavra, assim como com sua transmissão, em um povo de tradição oral.

3 Adinkra é um conjunto de ideogramas que compõem a escrita dos povos akan, da África Ocidental (Nascimento E. L., 2009). 
4. De acordo com Vieira (2017), a presença da população negra na cidade de Porto Alegre, apesar de ser conhecida desde o período colonial, não está nas narrativas oficiais sobre a evolução da cidade. Consequentemente, alguns espaços, antes ocupados pela população negra, foram gradativamente caindo no esquecimento. Entre essas regiões, estão: Areal da Baronesa, Colônia Africana, Ilhota, Parque da Redenção e Bacia do Mont Serrat.

$5 \quad$ Indumentária tradicional da cultura gaúcha.

\section{Referências}

Acorda. (2018). Intérprete: Agnes Mariá. Compositor: A. Mariá. Publicado pelo Canal Agnes Mariá, 9 out. 2018. 1 vídeo (3min. 20s.). Recuperado dehttps://www.youtube.com/ watch? $\mathrm{v}=$ QSo8FSnATr4\&ab channel=AgnesMari\%C3\%A1

A cultura em ação. Intérprete: Belchoficial. Compositor: Belchoficial. Publicado pelo Instagram@coletivo.universo,27 set.2019.1 vídeo (1min.). Recuperado de https://www.instagram.com/p/B27coeIArcJ/

Alves, M. C., Costa, E. S., \& Castelar, M. (2020). Psicologias Antirracistas: Desafios Epistemológicos, Metodológicos e Ético-Políticos. Psicol. Cienc. Prof., 4O(n.spe), e052019. http:// dx.doi.org/10.1590/1982-3703003052019

Asante, M. K. (2009). Afrocentricidade: notas sobre uma posição disciplinar. In E. L. Nascimento (Org.), Afrocentricidade: uma abordagem epistemológica inovadora (pp. 93-1 10). Selo Negro. Bâ, A. H. (2010). A tradição viva. In J. Ki-Zerbo, J. (Ed.), História Geral da África I: metodologia e pré-história da África (2 ed. rev., pp. 167-212). UNESCO. Recuperado de https://unesdoc. unesco.org/ark:/48223/pfooo0190249

Batista, A. (2016). Trajetos e percursos: das (im)possibilidades de enfrentamento do racismo dentro da academia. Trabalho de Conclusão de Curso, Faculdade de Psicologia, Universidade Federal do Rio Grande do Sul, Porto Alegre, RS. Recuperado de https://lume.ufrgs.br/hand$\underline{\mathrm{le} / 10183 / 157424}$

Carneiro, A. S. (2005). A Construção do Outro como Não-Ser como fundamento do Ser. Tese de Doutorado, Programa de Pós- graduação em Educação, Universidade de São Paulo, São Paulo, SP. Recuperado de https://negrasoulblog.files.wordpress.com/2016/04/a-construc3a7c3a3o-do-outro-como-nc3a 3o-ser-como-fundamento-do-ser-sueli-carneiro-tese 1.pdf

Carapeços, N. (2019). Poetry slam: competição de poesia falada ganha cada vez mais adeptos no Rio Grande do Sul. Gaúcha ZH, Porto Alegre, 21 ago. 2017. Cultura e Lazer, on-line, p. [1]. https://gauchazh.clicrbs.com.br/cultura-e-lazer/noticia/2017/08/poetry-slam competicao-de-poesia-falada-ganha-cada-vez-mais-adeptos-no-rio-grande-do-sul 9875439.html

Flôres, P., Galeano, G. B., Soares, H. B., \& Passos, R. F. (2021). O que pode a Psicologia Social com relação ao presente? Revista Polis e Psique, 11(1), 183-203. https://doi. org/10.22456/2238-152X.107984 
Fonseca, M. N. S. (2006). Literatura negra, literatura afro-brasileira: como responder à polêmica? In F. Souza \& M. N. Lima Orgs.), Literatura Afro-Brasileira (pp. 09-38). Centro de estudos afro-orientais/Fundação Palmares.

Gaia, R. S. P. \& Scorsolini-Comin, F. (2020). Candomblé Ketu e o sincretismo religioso no Brasil: perspectivas sobre as representações de Òsàlá na diáspora. Memorandum: Memória e História em Psicologia, vol. 37, 1-21. Recuperado de https://periodicos.ufmg.br/index.php/ memorandum/article/view/16346.

Jesus, J. O. (2019, jul./dez.). Rompendo silêncios: narrativas afrodescendentes no Brasil e na Alemanha. Leitura: Revista do programa de pós-graduação em linguística e literatura, 63, 247-259. https://www.seer.ufal.br/index.php/revistaleitura/article/view/5380/5664

Lorde, A. (2020). Irmã outsider: ensaios e conferências. Autêntica.

Marques, H. S. (2019). Jovem preto rei: nascido para vencer. Sonia Regina Bischain Rosa,

Mazama, A. (2009). AAfrocentricidade como um novo paradigma. In E. L. Nascimento (Org.), Afrocentricidade: uma abordagem epistemológica inovadora (pp. 111-127). Selo Negro.

Moore, C. (2012). Racismo e Sociedade Novas Bases Epistemológicas para entender o racismo. Geledés.

Nascimento, A. (2019). O quilombismo: Documentos de uma militância pan-africanista (4 ${ }^{\mathrm{a}} \mathrm{ed}$.). Ipeafro; Perspectiva.

Nascimento, B. (2006). O conceito de quilombo e a resistência cultural negra. In A. Ratts (Org.), Eu sou atlântica: sobre a trajetória de vida de Beatriz Nascimento (pp. 117-125). Imprensa Oficial/SP (IMESP). Recuperado de https://www.imprensaoficial.com.br/downloads/pdf/ projetossociais/eusouatlantica.pdf

Nascimento, E. L. (2009). Afrocentricidade: uma abordagem epistemológica inovadora. Selo Negro.

Nobles, W. W. (2009). Sakhu Sheti: Retomando e reapropriando um foco psicológico afrocentrado. In E. L. Nascimento (Org.), Afrocentricidade: uma abordagem epistemológica Inovadora (pp. 277-297). Selo Negro.

Oyěwùmí, O. (2002). Visualizando o corpo: teorias ocidentais e sujeitos africanos. In P. H. Coetzee \& A. P. J. Roux, A. P. J. (Eds.), The African Philosophy Reader (pp. 391-415). Routledge. Recuperado de https://filosofia-africana.weebly.com/uploads/1/3/2/1/13213792/oy\%C3\%A 8r\%C3\% B3nk\%E1\%BA\%B9\%CC\%81 oy\%C4\%9Bw\%C3\%B9m\%C3\%AD - visualizando o corpo.pdf

Ramose, M. B. (2011). Sobre a Legitimidade e o Estudo da Filosofia Africana. Ensaios Filosóficos, 4, 06-25. Recuperado de https://filosofia-africana.weebly.com/uploads/1/3/2/1/13213792/ mogobe b. ramose - sobre a legitimidade e o estudo da filosofia africana.pdf

Ratts, A. (2006). Eu sou atlântica: sobre a trajetória de vida de Beatriz Nascimento. Imprensa Oficial/SP (IMESP). Recuperado de https://www.imprensaoficial.com.br/downloads/pdf/ projetossociais/eusouatlantica.pdf

Silva, R. N. (2004). Notas para uma genealogia da Psicologia Social. Psicol. Soc., 16(2), 12-19. https://doi.org/10.1590/S0102-71822004000200003

Soares, L. V. \& Machado, P, S. (2017). "Escrevivências" como ferramenta metodológica na produção de conhecimento em Psicologia Social. Revista Psicologia Política, 17(39), 203219. Recuperado de http://pepsic.bvsalud.org/scielo.php? script=sci arttext\&pid=S1519-549X2017000200002 
Tem Preto no Sul. (2018). Intérprete: Bruno Negrão e Cristal Rocha. Publicado no Canal Bruno Negrão, 12 nov. 2018. 1 vídeo (3min. 20s.).https://www.youtube.com/ $\underline{\text { watch} ? \mathrm{v}=\text { EhOIX } 8 p p n I A \& \mathrm{t}=75 \mathrm{~s}}$

Vergne, C. M., Vilhena, J., Zamora, M. H. \& Rosa, C. M. (2015). A palavra é... genocídio: a continuidade de práticas racistas no Brasil. Psicologia \& Sociedade, 27(3), 516-528. https:// doi.org/10.1590/1807-03102015v27n3p516

Vieira, D. M. (2017). Territórios negros em Porto Alegre/RS (1800 - 1970): geografia histórica da presença negra no espaço urbano. Dissertação de Mestrado, Instituto de Geociências, Universidade Federal do Rio Grande do Sul, Porto Alegre, RS, 2009. Recuperado de https://www.lume. ufrgs.br/handle/10183/177570

Zamora, M. H. R. N. (2012). Desigualdade Racial, racismo e seus efeitos. Fractal, Revista de Psicologia, 24(3), 563-578. Recuperado de https://www.scielo.br/pdf/fractal/v24n3/o9.pdf

\section{MAÍNE ALVES PRATES \\ https://orcid.org/0000-0002-3673-3519}

Psicóloga. Mestre em Psicologia Social e Institucional pela UFRGS.

E-mail: mainealvespratesn@gmail.com

\section{NEUZA MARIA DE FÁTIMA GUARESCHI \\ https://orcid.org/0000-0001-5892-188X}

Professora adjunta do Programa de Pós-Graduação em Psicologia Social e Institucional do Instituto de Psicologia da Universidade Federal do Rio Grande do Sul. É também doutora em Educação pela University of Wisconsin, nos Estados Unidos. Além disso, é mestre e psicóloga pela Pontifícia Universidade Católica do Rio Grande do Sul.

E-mail: nmguares@gmail.com

\section{CAROLINA DOS REIS}

\section{https://orcid.org/0000-0001-6482-2677}

Doutora em Psicologia Social e Institucional e professora do Programa de Pós-Graduação em Psicologia Social e Institucional da Universidade Federal do Rio Grande do Sul.

E-mail: carolinadosreis@gmail.com 


\begin{tabular}{|c|c|}
\hline Histórico & $\begin{array}{l}\text { Submissão: 29/04/2021 } \\
\text { Revisão: 28/10/2021 } \\
\text { Aceite: 28/10/2021 }\end{array}$ \\
\hline $\begin{array}{l}\text { Contribuição } \\
\text { dos autores }\end{array}$ & $\begin{array}{l}\text { Concepção: M.A.P.; N.M.F.G.; C.R. } \\
\text { Coleta de dados: M.A.P.; N.M.F.G.; C.R. } \\
\text { Análise de dados: M.A.P.; N.M.F.G.; C.R. } \\
\text { Elaboração do manuscrito: M.A.P.; N.M.F.G.; C.R. } \\
\text { Revisões críticas de conteúdo intelectual importante: } \\
\text { MM.A.P.; N.M.F.G.; C.R. } \\
\text { Aprovação final do manuscrito: M.A.P.; N.M.F.G.; C.R. }\end{array}$ \\
\hline Financiamento & 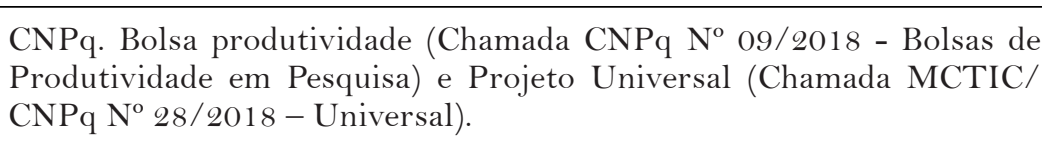 \\
\hline $\begin{array}{l}\text { Aprovação, ética } \\
\text { e consentimento }\end{array}$ & $\begin{array}{l}\text { O estudo seguiu as normativas da RESOLUÇÃO No } 510 \text {, DE o7 DE } \\
\text { ABRIL DE } 2016 \text { sobre pesquisa em Ciências Humanas e Sociais. }\end{array}$ \\
\hline
\end{tabular}

